\title{
EXTRACTION AND CHARACTERIZATION OF PHENOLIC COMPOUNDS AND DIETARY FIBRES FROM BANANA PEEL
}

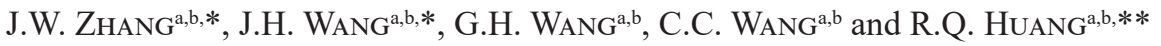

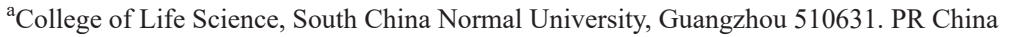 \\ ${ }^{\mathrm{b}}$ Guangdong Provincial Engineering Technology Research Center for Drug and Food Biological Resources \\ Processing and Comprehensive Utilization, Guangzhou 510631. PR China
}

(Received: 6 May 2019; accepted: 5 July 2019)

\begin{abstract}
Phenolic extract from banana peel was extracted with $95 \%$ ethanol and characterized by LC-TOF-MS/MS. Epicatechin, rutin, 3,4-dihydroxybenzaldehyde, 3,4-dihydroxybenzoic acid, myricetin, ferulic acid, chlorogenic acid, and gallic acid were detected in the extract. Cholate test was performed for the initial examination of the hypolipidemic effect of the dietary fibres. The dietary fibres prepared by sequential treatment with sulphuric acid then sodium hydroxide (SST) and sodium hydroxide treatment (SHT) had high water-holding capacities (7.48 and $\left.6.91 \mathrm{~g} \mathrm{~g}^{-1}\right)$ and swelling capacities $\left(4.8\right.$ and $\left.4.3 \mathrm{ml} \mathrm{g}^{-1}\right)$. The dietary fibres prepared by sequential treatment with trypsin then sulphuric acid (TST) and sulphuric acid treatment (SAT) had high oil-holding capacities (5.52 and 5.10 $\mathrm{g} \mathrm{g}^{-1}$ ) and enhanced capacities for sodium cholate adsorption. Results indicated the potentials of banana peel as functional ingredient in food applications.
\end{abstract}

Keywords: banana peel, phenolic extract, LC-TOF-MS/MS, dietary fibres, hypolipidemic

Banana (Musa acuminata) is one of the most consumed fruits in the world. It is widely planted and harvested with more than 5.4 million hectares around the world and more than 113 million metric tons were produced in 2016 (FAOSTAT, 2016). The major waste stream after processing banana is banana peel, which weighs approximately $30 \%$ of the banana fruit, but was only reutilized as animal feed, organic fertilizer, and adsorbent for water purification process (BAKRY et al., 1997; ANNADURAI et al., 2002). In the daily household and fresh consumption sectors, preliminary investigation suggested that several tons of banana peel is produced daily (ANWAR et al., 2010).

As an agro-waste, banana peel contains phytonutrients, minerals, vitamins, and dietary fibers and has antioxidant activities (SINGH et al., 2016). From previous research, banana peel helped to reduce the absorption of cholesterol and improve blood glucose and lipid levels in mice (WACHIRASIRI et al., 2009). It was also shown that banana peel provided protection against coronary heart disease, cancer, cardiovascular disease, and autoimmune disease (NIJVELDT et al., 2001). In addition, the viability of Saccharomyces cerevisiae would increase in dough by substituting the Iraqi flour with $10 \%$ of banana peel flour (AL-SAHLANY \& ALMUSAFER, 2018).

Liquid chromatography-mass spectrometry (LC-MS) has been the most commonly used analytical technique for the identification and quantification of phenolic compounds (DUCKSTEIN \& STINTZING, 2011). However, characterization of phenolic compounds using LCTOF-MS/MS is rarely reported, therefore, this study investigated the chemical profile of the phenolic extract from banana peel with LC-TOF-MS/MS.

\footnotetext{
* J.W. ZHANG and J.H. WANG contributed equally to the work.

** To whom correspondence should be addressed.

Phone: +86 20 13925120692; fax: +86 20 85211372; e-mail: hruqiang@scnu.edu.cn
} 
In this research, four different preparation methods were used for the preparation of dietary fibres from banana peel, and the physical and chemical properties were determined. This study aimed to aquire baseline data for the phenolic profile and the functionality of dietary fibres from banana peels in the Southern China region.

\section{Materials and methods}

\subsection{Materials}

1.1.1. Chemicals. Gallic acid was purchased from the National Institute for the Control of Pharmaceutical and Biological products (Beijing, China). Porcine trypsin, sodium cholate, sodium taurocholate and sodium glycocholate were purchased from Sigma Chemical Co. (St. Louis, MO, USA). HPLC grade methanol was purchased from Burdick \& Jackson (Muskegon, MI, USA). Other chemicals and solvents were of analytical grade.

1.1.2. Preparation of banana peel powder. Banana peel was collected from Guangzhou Medicine Market (Guangzhou, Guangdong, China). It was cleaned, dried, ground, and passed through a 40 -mesh screen, and then stored at $4-8{ }^{\circ} \mathrm{C}$ for further analysis.

1.1.3. Preparation of phenolic extract powder from banana peel. $100 \mathrm{~g}$ of banana peel was weighed, sliced, and blanched in boiling water for $5 \mathrm{~min}$ to deactivate polyphenol oxidase. After extracting with $50 \mathrm{ml} \mathrm{95 \%} \mathrm{ethanol} \mathrm{for} 60 \mathrm{~min}$, the slurry was centrifuged at 10000 r.p.m. for $15 \mathrm{~min}$. The phenolic extract powder was freeze-dried to be analyzed further.

\subsection{Determination of total phenolic content}

Total phenolic content (TPC) of the extract was determined with Folin-Ciocalteu method (SINGLETON et al., 1999) with a UV spectrophotometer (UV2550, Shimadzu, Japan).

\subsection{LC-TOF-MS/MS analysis on phenolic compositions in the phenolic extract}

The phenolic extract powder from banana peel was dissolved in methanol and analyzed with Shimadzu LC-20 HPLC system (Kyoto, Japan) and Triple-TOF ${ }^{\mathrm{TM}} 5600$ Mass spectrometer (AB-SCIEX, USA). Analytes were separated by Phenomenex column Luna-C18 $(3.0 \mathrm{~mm}$ $\times 150 \mathrm{~mm}$ ) at a flow rate of $0.8 \mathrm{ml} \mathrm{min}{ }^{-1}$ at $40{ }^{\circ} \mathrm{C}$. The mobile phase consisted of eluent $\mathrm{A}$ (deionized water) and eluent B (methanol) with gradient elution: $0-3 \mathrm{~min}, \mathrm{~B}$ from $10 \%$ to $90 \%$ and maintained to $10 \mathrm{~min} ; 10-15 \mathrm{~min}, 90 \% \mathrm{~A}$. The injection volume was set at $10 \mu \mathrm{l}$. The MS conditions were set as follows: positive ion mode, desolvation gas flow at $6001 \mathrm{~h}^{-1}$ at $550{ }^{\circ} \mathrm{C}$, cone gas flow at $60 \mathrm{~h} \mathrm{~h}^{-1}$ and source temperature at $100^{\circ} \mathrm{C}$, collision energy $10.0 / 35$ $\mathrm{V}$, nebulizer pressure $55 \mathrm{psi}$, ionization voltage $4.5 \mathrm{kV}$, scan range $100-1000 \mathrm{~m} \mathrm{z}^{-1}$.

\subsection{Extraction of banana peel dietary fibres}

Water-insoluble dietary fibres (IDF) from banana peel were extracted by four methods as follows.

1.4.1. Sulphuric acid treatment (SAT). Ten g of banana peel powder (see 1.1.2.) was mixed with $150 \mathrm{ml}$ of $0.005 \mathrm{~mol} \mathrm{l}^{-1} \mathrm{H}_{2} \mathrm{SO}_{4}$. The mixture was constantly shaken at $50{ }^{\circ} \mathrm{C}$ for 1 
$\mathrm{h}$ and filtered. The residue was washed twice with $200 \mathrm{ml} \mathrm{95 \%} \mathrm{ethanol} \mathrm{and} \mathrm{dried} \mathrm{to} \mathrm{obtain}$ IDF.

1.4.2. Sodium hydroxide treatment (SHT). Ten g of banana peel powder (see 1.1.2.) was mixed with $150 \mathrm{ml}$ of $10^{-4} \mathrm{~mol} \mathrm{l}^{-1} \mathrm{NaOH}$. The mixture was constantly shaken at $50{ }^{\circ} \mathrm{C}$ for $1 \mathrm{~h}$ and filtered. The residue was washed twice with $200 \mathrm{ml}$ 95\% ethanol and dried to obtain IDF.

1.4.3. Sequential treatment with sulphuric acid and sodium hydroxide (SST). To produce SST fibre, the filtered wet residue before drying from SAT was further treated with sodium hydroxide. $150 \mathrm{ml}$ of $0.005 \mathrm{~mol} \mathrm{l}^{-1} \mathrm{NaOH}$ was added to filtered residue at a liquid-solid ratio of $15: 1 \mathrm{ml} \mathrm{g}^{-1}$ with constant shaking for $1 \mathrm{~h}$ at $50{ }^{\circ} \mathrm{C}$. Then the residue was washed twice with $200 \mathrm{ml} \mathrm{95 \%} \mathrm{ethanol} \mathrm{and} \mathrm{dried} \mathrm{to} \mathrm{obtain} \mathrm{IDF.}$

1.4.4. Sequential treatment with trypsin and sulphuric acid (TST). Of porcine trypsin solution ( $\left.0.6 \mathrm{mg} \mathrm{ml}^{-1}, \mathrm{pH} 8.0\right) 125 \mathrm{ml}$ was added to $10 \mathrm{~g}$ of banana peel powder (see 1.1.2.) at $45^{\circ} \mathrm{C}$ with constant shaking for $2.5 \mathrm{~h}$. After filtering, $150 \mathrm{ml}$ of $0.005 \mathrm{~mol} \mathrm{l}^{-1} \mathrm{H}_{2} \mathrm{SO}_{4}$ was added at a liquid-solid ratio of $15: 1 \mathrm{ml} \mathrm{g}^{-1}$ with constant shaking for $1 \mathrm{~h}$ at $50{ }^{\circ} \mathrm{C}$. The residue was washed twice with $200 \mathrm{ml}$ 95\% ethanol and dried to obtain IDF.

\subsection{Physical and chemical properties of dietary fibres}

1.5.1. Water-holding capacity, swelling capacity, and oil-holding capacity. Water-holding capacity, swelling capacity and oil-holding capacity were determined based on the methods of RAGHAVENDRA and co-workers. (2004) and KHAN and co-workers. (2018).

1.5.2. In vitro bile salt adsorption capacity. In vitro bile salt adsorption capacity of banana dietary fibre was determined based on the method of XIE and co-workers (2017) using sodium cholate (SC), sodium taurocholate (STC), and sodium glycocholate (SGC).

\subsection{Statistical analysis}

The ANOVA test was performed to analyze the statistical significances, and results were expressed as mean \pm SD with SPSS 19.0. Origin 8.5 software was used to generate the graphs.

\section{Results and discussion}

\subsection{Quantification and identification of polyphenolic compounds}

2.1.1. Total phenolic content. The extraction method yielded $28.61 \mathrm{~g}$ of polyphenolic extract powder. Total phenolic content in the polyphenolic extract powder was $23.33 \pm 1.59$ gallic acid equivalent (GAE) $\mathrm{mg} \mathrm{g}^{-1}$ powder. The yield of polyphenolic content from banana peel was $0.67 \%$. The total polyphenolic content obtained from this study was in the range of $0.62 \sim 0.71 \mathrm{mg} \mathrm{GAE} / \mathrm{g}$. Total phenolic content from banana flour (Musa AAA) was tested at $29.2 \pm 0.8 \mathrm{mg} \mathrm{GAE} / \mathrm{g}$ of dry sample (REBELLO et al., 2014).

2.1.2. Identification of phenolic compositions. The chemical composition of the phenolic extract from banana peel was determined by LC-TOF-MS/MS analysis. The extraction ion chromatograms and mass spectrum for the polyphenol compounds are shown in Figures 1-5. Table 1 summarizes the main parameter obtained when the accurate mass, retention time, empirical formula, mass errors, masses of the fragment ions, and their elemental compositions 
were used as parameters. The identification of detected polyphenols in the LC-TOF-MS/MS analysis was conducted based on the previous studies identifying the chemical compounds (Wiley Compound SearchSM; Gomes et al., 2013; Wu et al., 2015). Figure 1 shows that the retention time (Rt, $\mathrm{min}$ ) of compounds $1-8$ were $6.80,6.65,6.74,6.92,7.27,8.4,11.4$, and $10.21 \mathrm{~min}$, respectively. As a result, the eight following polyphenols were detected using LCTOF-MS/MS: 3,4-dihydroxybenzaldehyde, 3,4-dihydroxybenzoic acid, epicatechin, rutin, ferulic acid, chlorogenic acid, myricetin, and gallic acid.

Studies on the phenolic composition of banana peel are limited. REBELLO and co-workers (2014) extracted banana peel compounds with methanol, water and formic acid and detected 10 types of flavanols including rutin and myricetin. The extract from banana peel also contained 3,4-dihydroxybenzaldehyde and 3,4-dihydroxybenzoic acid, which behave as fungistatic substances (MulvENA et al., 1969; WATANABE et al., 1997). Epicatechin, catechin, and gallocatechin were also found among water extracted polyphenols from banana peel (SOMEYA et al., 2002). Ferulic acid, chlorogenic acid, gallic acid, and 3,4-dihydroxybenzoic acid among polyphenols from banana peel were also proven to have high antioxidant activity (BALASUNDRAM et al., 2006).

\subsection{Physicochemical properties of dietary fibre}

2.2.1. Total dietary fibre and fractionated fibres. Many reports have studied the total dietary fibres and the fractionated fibres from banana. Compared with $14.5 \%$ dietary fibre of banana fruit (JUAREZ-GARCIA et al., 2006), the dietary fibre content of banana peel is generally higher, ranging from $32 \%$ to $50.25 \%$ (RANZANI et al., 1996; EMAGA et al., 2008; WACHIRASIRI et al., 2009). MENEZES and co-workers (2011) reported 56.25\% dietary fibre was from unripe banana flour (fruit and peel). Data from this study was $49.61 \pm 0.30 \%$, and the total fibres with SAT, SHT, SST, TST treatments were $54.39 \pm 1.10 \%, 53.31 \pm 0.70 \%, 52.97 \pm 0.20 \%$, and $54.58 \pm 1.20 \%$, respectively.

2.2.2. Water-holding capacity, swelling capacity, and oil-holding capacity. Fibre with high water-holding capacity can increase the volume of excrement, speed up defecation, reduce rectal pressure, and prevent constipation. As shown in Figure 6(A), extraction processes, except for SAT, can significantly improve the water-holding capacity of the total banana peel fibres. SST provided the best water-holding capacity, with a holding capacity of $7.48 \mathrm{~g} \mathrm{~g}^{-1}$. In a single process, the dietary fibre obtained by SHT has better water-holding capacity $\left(6.91 \mathrm{~g} \mathrm{~g}^{-1}\right)$ than SAT $\left(6.35 \mathrm{~g} \mathrm{~g}^{-1}\right)$. Therefore, to obtain better water-holding capacity of banana peel dietary fibre, the use of SST, SHT, and TST should be considered.

As the absorption of the dietary fibre increases, the volume of the gastrointestinal tract increases. Although this increase easily leads to satiety, it also affects the body's absorption of other ingredients in food, which is crucial to obesity prevention. Dietary fibre swelling in colon increases the volume of manure and reduces the concentration of carcinogenic factors. These effects are conducive to colon function and prevent colon cancer. As shown in Figure 6(B), the swelling capacities of the dietary fibres obtained using SST (4.8 $\left.\mathrm{ml} \mathrm{g}^{-1}\right)$ and SHT $\left(4.3 \mathrm{ml} \mathrm{g}^{-1}\right)$ were significantly higher than those of TST $\left(2.6 \mathrm{ml} \mathrm{g}^{-1}\right)$, indicating that sulphuric acid significantly reduces the swelling capacity of dietary fibres, whereas sodium hydroxide improves swelling capacity. The acid-base combination of banana peel dietary fibre dilatants may be related to the order of acid-base treatment. Thus, the experiment using acid-base treatment sequence led to a significantly improved final fibre swelling capacity. 


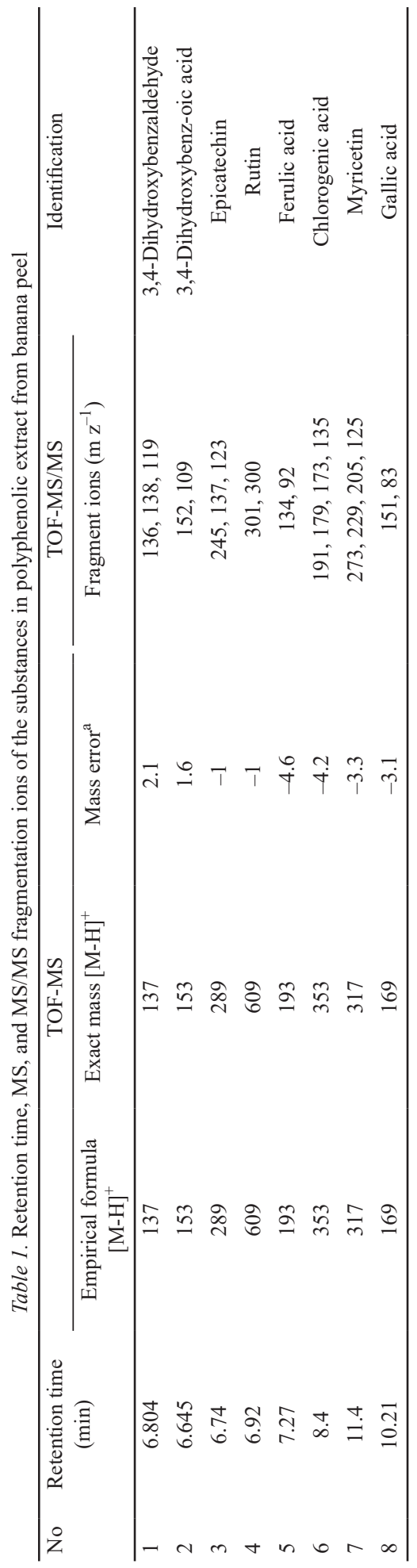



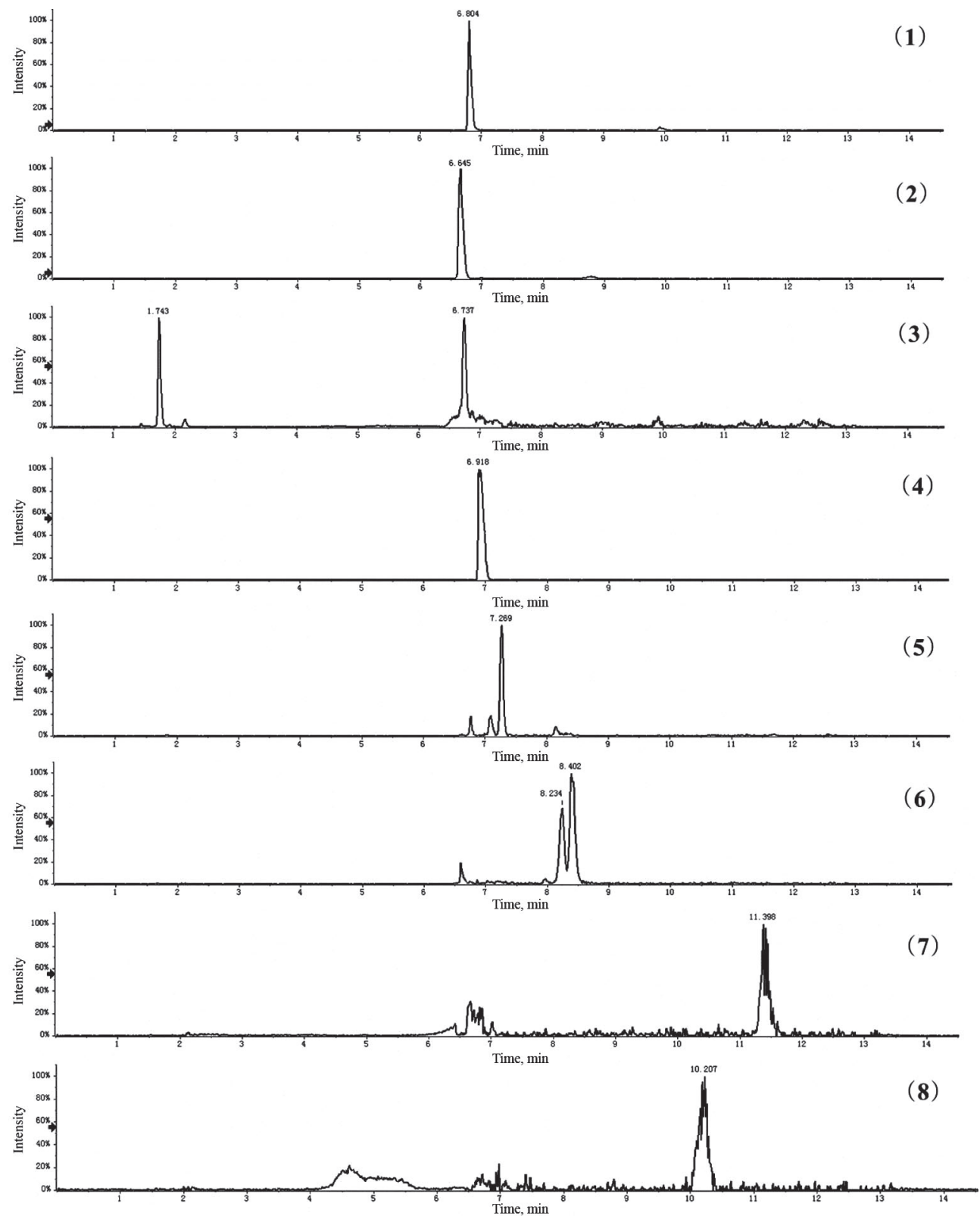

Fig. 1. Extraction chromatograms for seven tentative polyphenols analysed by HPLC

(1: 3,4-dihydroxybenzaldehyde; 2: 3,4-dihydroxybenzoic acid; 3: epicatechin; 4: rutin; 5: ferulic; 6: chlorogenic acid; 7: myricetin; 8: gallic acid) 

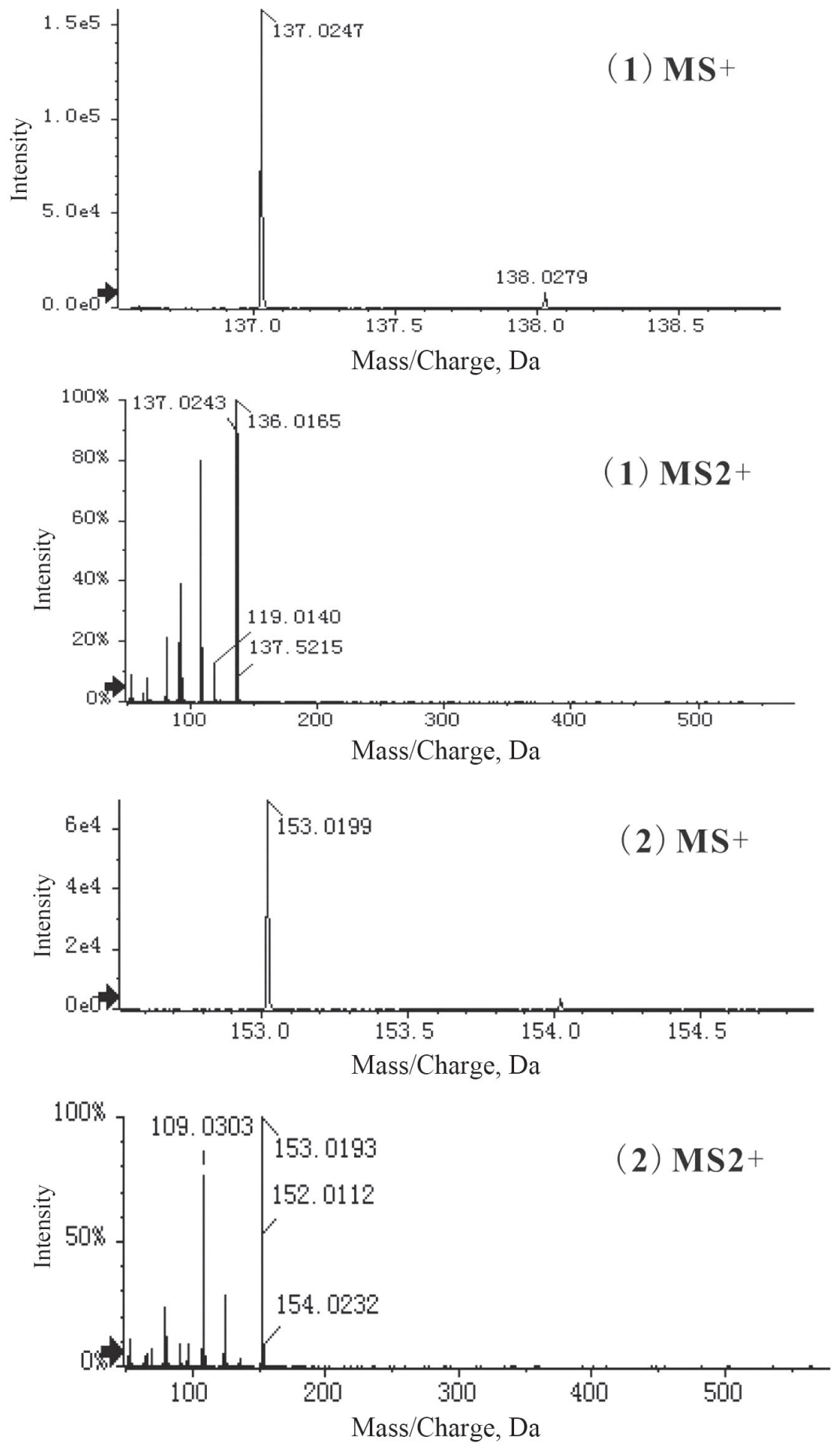

Fig. 2. Mass spectrum of the identified polyphenols (1: 3,4-dihydroxybenzaldehyde; 2: 3,4-dihydroxybenzoic acid) 

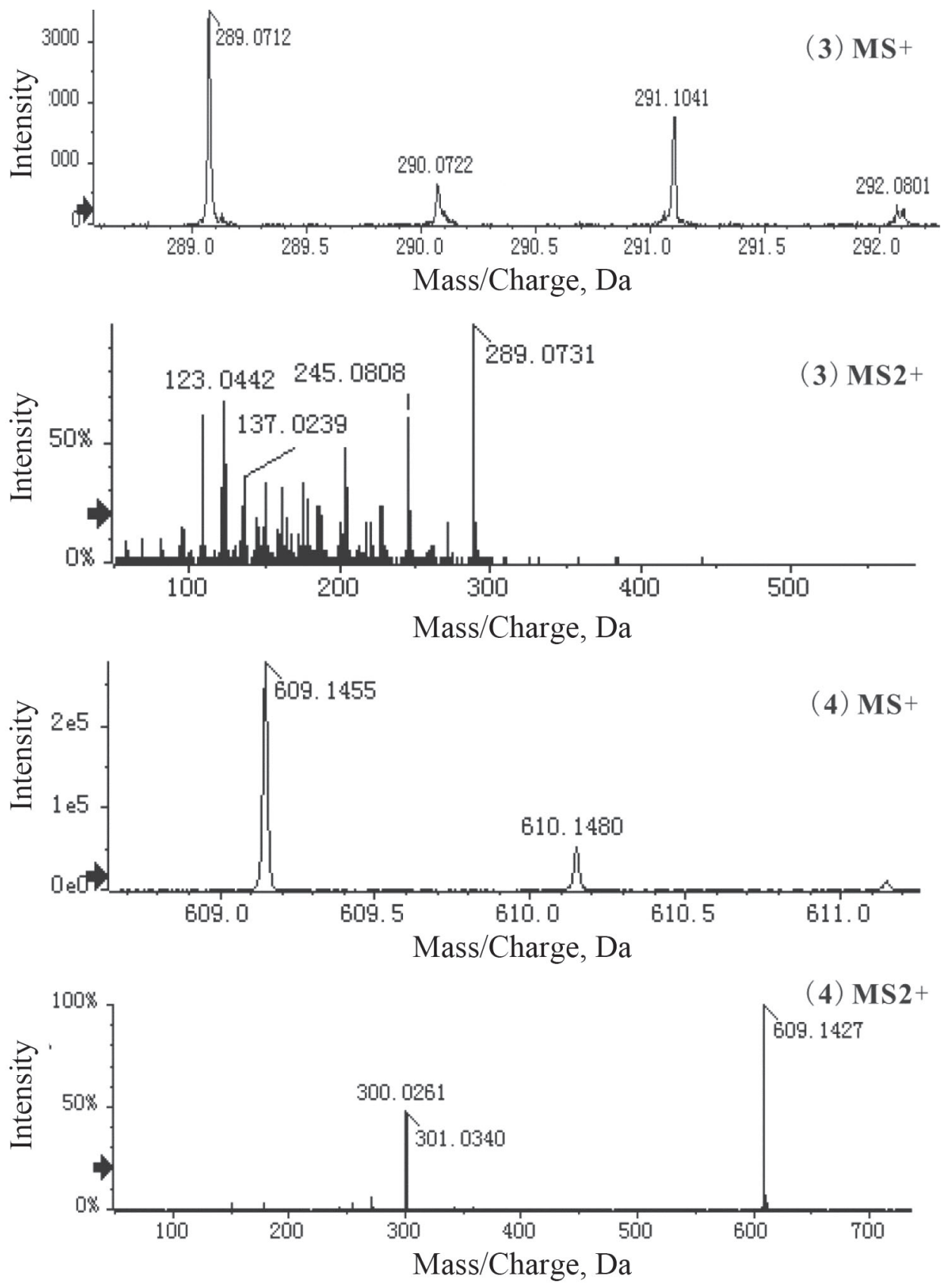

Fig. 3. Mass spectrum of the identified polyphenols (3: epicatechin; 4: rutin) 

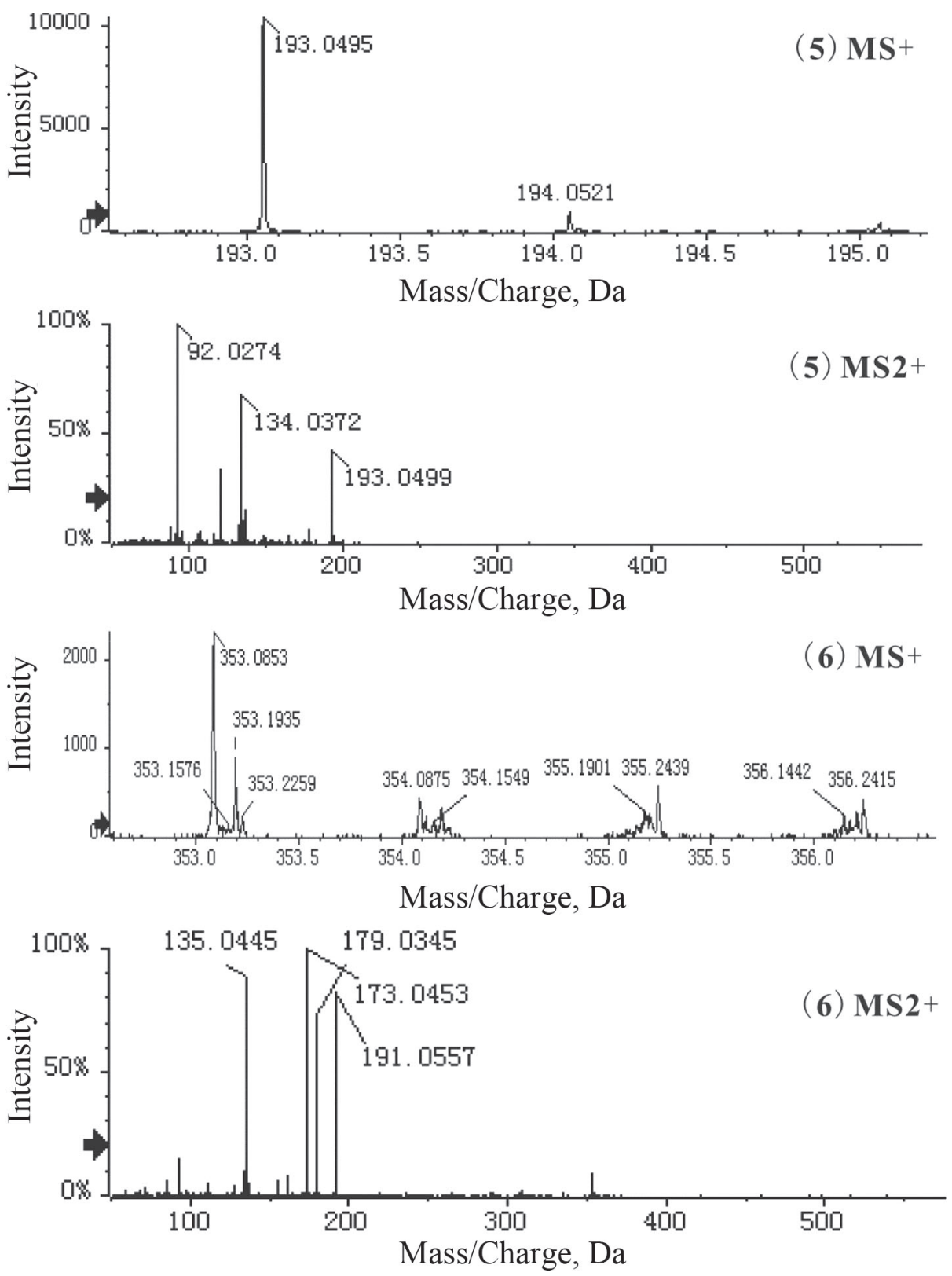

Fig. 4. Mass spectrum of the identified polyphenols (5: ferulic; 6: chlorogenic acid) 

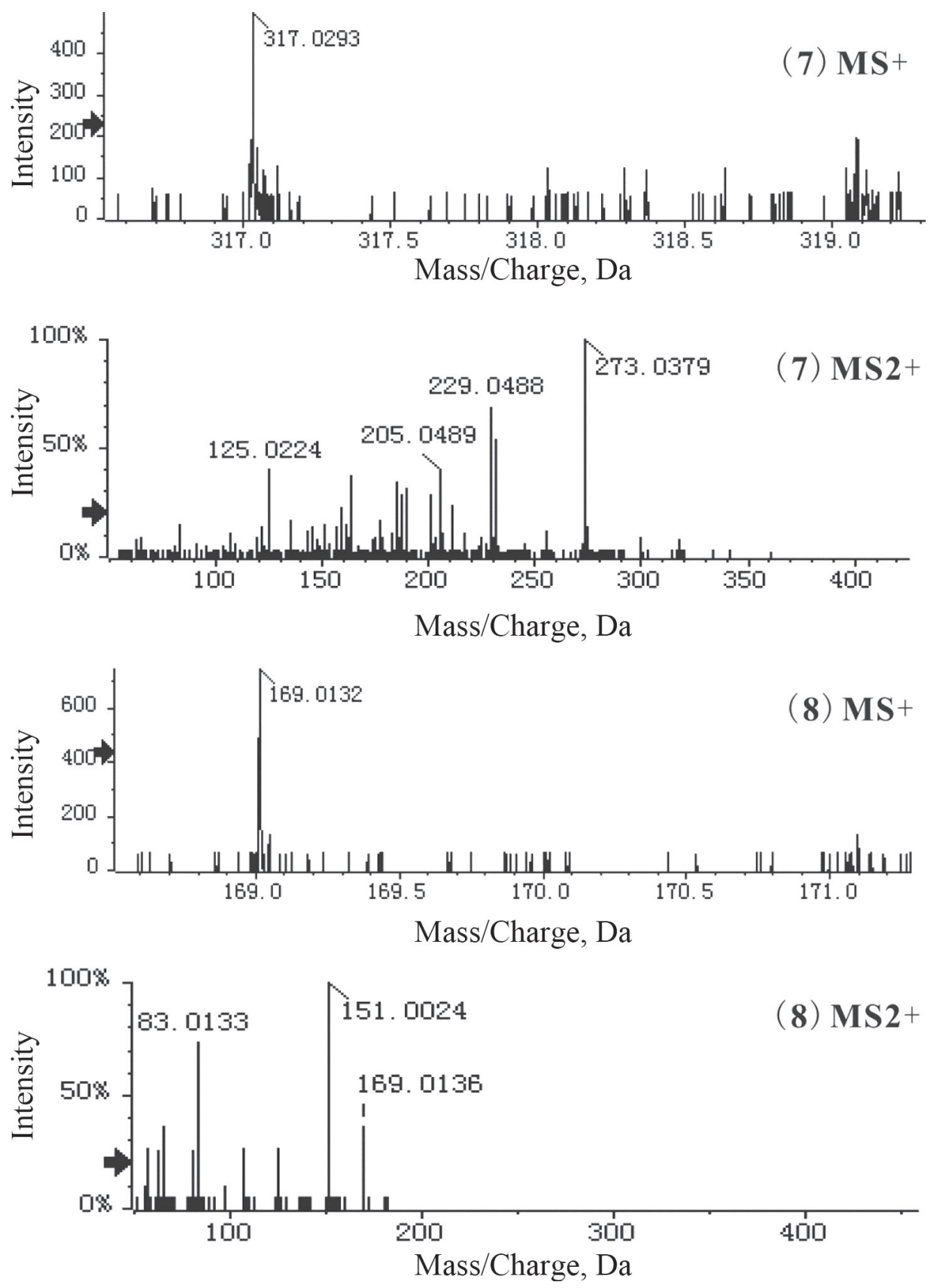

Fig. 5. Mass spectrum of the identified polyphenols (7: myricetin; 8: gallic acid) 

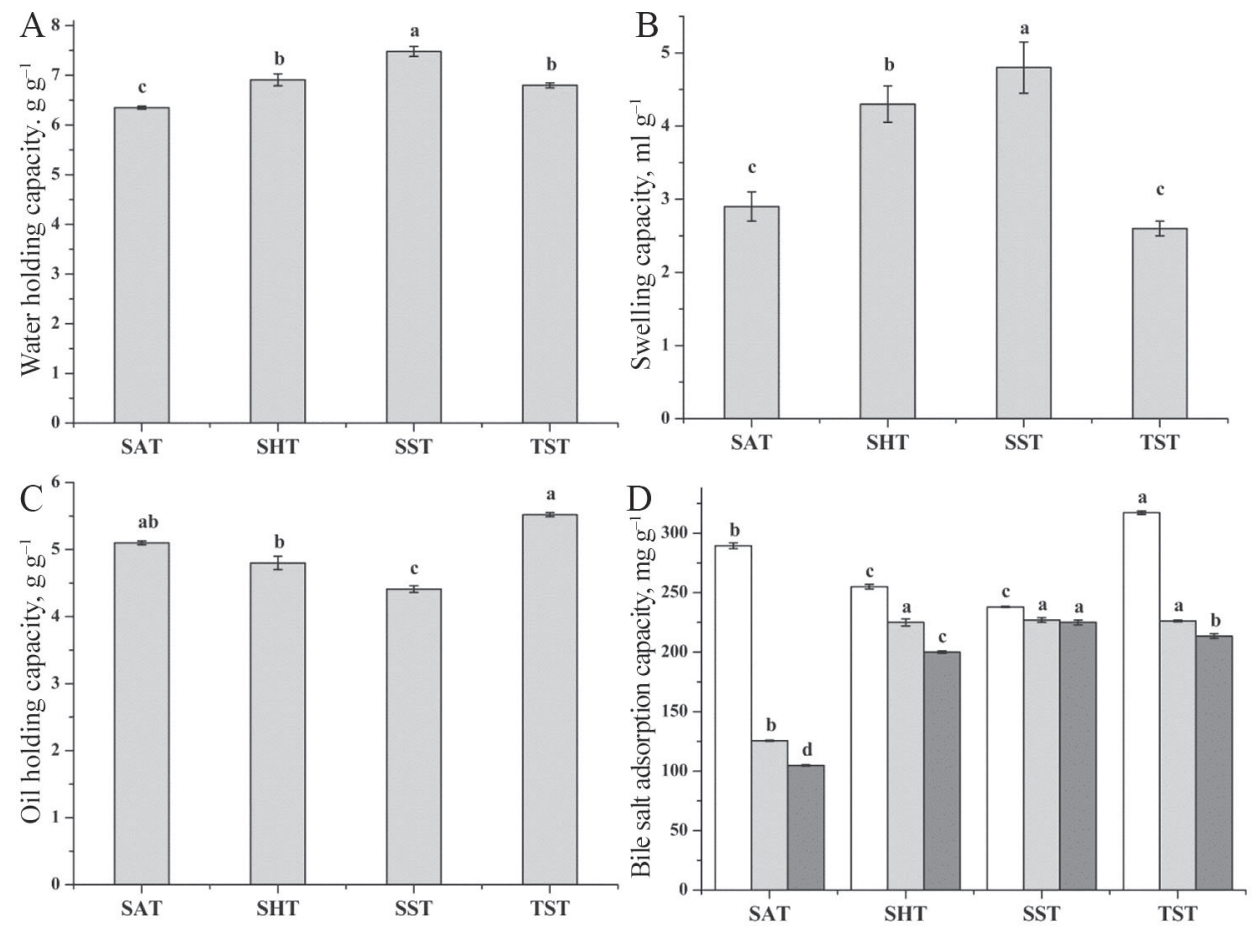

Fig. 6. Effects of preparation technology on the water-holding capacity (A), swelling capacity (B), oil-holding capacity (C), and bile salt adsorption capacity (D) of banana peel dietary fibre (SAT: sulphuric acid treatment; SHT: sodium hydroxide treatment; SST: sequential treatment with sulphuric acid followed by sodium hydroxide; TST: sequential treatment with trypsin followed by sulphuric acid; SC: sodium cholate; STC: sodium taurocholate; SGC: sodium glycocholate. Values are means \pm SD of three independent experiments. Values not sharing the same letter are significantly different $(\mathrm{P}<0.05)$.)

$\mathrm{D}: \square: \mathrm{SC} ; \quad$ :STC; $:$ SGC

Dietary fibre in the human gut can absorb fat, thereby reducing the fat absorption and subsequent excessive fat accumulation in the body. Dietary fibres wrap fat, thereby preventing interaction between fat and bile, and consequently reducing the intestinal absorption of cholesterol in the diet. Figure 6(C) shows that banana peel fibres with SST treatment had the lowest $\left(4.41 \mathrm{~g} \mathrm{~g}^{-1}\right)$ and TST had the highest oil-holding capacity $\left(5.52 \mathrm{~g} \mathrm{~g}^{-1}\right)$.

2.2.3. In vitro bile salt adsorption capacity. Bile acids are biosynthesized from cholesterol in the liver, and excess cholesterol in the blood causes cardiovascular disease (XIE et al., 2017). The adsorption of bile acids is considered as one of the mechanisms of the lipidlowering functions of dietary fibres. Dietary fibres promote cholate salt excretion through adsorption promoting the metabolism of cholesterol, reduce the reabsorption of bile acids, and block the enterohepatic circulation of cholesterol to reduce the cholesterol levels. Therefore, the ability of dietary fibres to adsorb cholate shows their functions in blood lipid regulation. As shown in Figure 6(D), the adsorption values of the dietary fibres from banana peel followed the order: SC $>$ STC $>$ SGC. Compared to SHT and SST, SAT $\left(289.4 \mathrm{mg} \mathrm{g}^{-1}\right)$ and TST (317.2 $\mathrm{mg} \mathrm{g}^{-1}$ ) showed higher SC adsorption values, while SAT showed the lowest STC 
(125.6 $\left.\mathrm{mg} \mathrm{g}^{-1}\right)$ and SGC (104.8 $\left.\mathrm{mg} \mathrm{g}^{-1}\right)$ adsorption values. In general, TST showed high adsorption values of the dietary fibres in SC, STC (226.2 $\left.\mathrm{mg} \mathrm{g}^{-1}\right)$, and SGC (213.5 $\left.\mathrm{mg} \mathrm{g}^{-1}\right)$. These results show that dietary fibres from banana peel have a certain hypolipidemic effect.

\section{Conclusions}

The experimental results show that banana peel extract contains several polyphenolic compounds, and the composition, physical and chemical properties of dietary fibres from banana peel varies among extraction methods. Dietary fibres from banana peel have a certain hypolipidemic effect, which shows a potential in application with agricultural waste.

$*$

The research was supported by Guangzhou Research Collaborative Innovation Projects (201604020068), Guangzhou Science and Technology Program key projects (201707010372).

\section{References}

Al-Sahlany, S.T.G \& Al-Musafer, A.M.S. (2018): Effect of substitution percentage of banana peels flour in chemical composition, rheological characteristics of wheat flour and the viability of yeast during dough time. J. Saudi Soc. Agr. Sci., https://doi.org/10.1016/j.jssas.2018.06.005.

AnNADURAI, G., JuAnG, R.S. \& LeE, D.J. (2002): Use of cellulose-based wastes for adsorption of dyes from aqueous solutions. J. Hazard. Mater, 92(3), 263-274.

Anwar, J., Shafique, U., Salman, M., Dar, A. \& Anwar, S. (2010): Removal of Pb (II) and Cd (II) from water by adsorption on peels of banana. Bioresour. Technol., 101, 1752-1755.

Bakry, F., Carreel, F., Caruana, M.L., Côte, F.-X., Jenny, C. \& Télenas du Montcel, H. (1997): Les bananiers. -in: Charrier, A., Jacquot, M., Serge, H. \& Nicolas, D. (Eds) L'amélioration des plantes tropicales. $1^{\mathrm{st}} \mathrm{ed}$., CIRAD ORSTOM, France. pp. 109-139.

Balasundram, N., Sundram, K. \& Samman, S. (2006): Phenolic compounds in plants and agri-industrial byproducts: Antioxidant activity, occurrence, and potential uses. Food Chem., 99(1), 191-203.

Duckstein, S. \& Stintzing, F. (2011): Investigation on the phenolic constituents in Hamamelis virginiana leaves by HPLC-DAD and LC-MS/MS. Anal. Bioanal. Chem., 401, 677-688.

Emaga, T.H., Robert, C., Ronkart, S.N., Wathelet, B. \& Paquot, M. (2008): Dietary fibre components and pectin chemical features of peels during ripening in banana and plantain varieties. Bioresour. Technol., 99, 43464354.

FAOSTAT, 2016. http://www.fao.org/faostat/en/\#data/QC (last accessed 4 July 2019).

Gomes, E.D.B., Ramalho, S.A., Gualberto, N.C., Miranda, R.D.C.M.D, Nigam, N. \& Narain, N. (2013): A rapid method for determination of some phenolic acids in Brazilian tropical fruits of mangaba (Hancornia speciosa Gomes) and umbu (Spondias tuberosa Arruda Camara) by UPLC. JASMI, 3(3), 1.

Juarez-Garcia, E., Agama-Acevedo, E., Sáyago-Ayerdi, S.G., Rodriguez-Ambriz, S.L. \& Bello-Perez, L.A. (2006): Composition, digestibility and application in breadmaking of banana flour. Plant Foods Hum. Nutr., $61(3), 131$.

Khan, G.M., Khan, N.M., Khan, Z.U., Ali, F., Jan, A.K., ... \& Elahi, R. (2018): Effect of extraction methods on structural, physiochemical and functional properties of dietary fiber from defatted walnut flour. Food Sci. Biotechnol., 27, 1015-1022.

Menezes, E.W., Tadini, C.C., Tribess, T.B., Zuleta, A., Binaghi, J., PaK, N., .. \& Lajolo, F.M. (2011): Chemical composition and nutritional value of unripe banana flour (Musa acuminata, var. Nanicão. Plant Foods Hum. Nutr., 66(3), 231-237.

Mulvena, D., Webb, E.C. \& Zerner, B. (1969): 3,4-Dihydroxybenzaldehyde, a fungistatic substance from green Cavendish bananas. Phytochemistry, 8, 393-395. 
Nijveldt, R.J., Van Nood, E.L.S., Van Hoorn, D.E., Boelens, P.G., Van Norren, K. \& Van Leeuwen, P.A. (2001): Flavonoids: a review of probable mechanisms of action and potential applications. Am. J. Clin. Nutr., 74(4), $418-425$.

Raghavendra, S.N., Rastogi, N.K., Raghavarao, K.S.M.S. \& Tharanathan, R.N. (2004): Dietary fiber from coconut residue: Effect of different treatments and particle size on the hydration properties. Eur. Food Res. Technol., 218, 563-567.

Ranzani, M.R., Sturion, G.L. \& Bicudo, M.H. (1996): Chemical and biological evaluation of ripe banana peel. Arch. Latinoam. Nutr., 46(4), 320-324.

Rebello, L.P.G., Ramos, A.M., Pertuzatti, P.B., Barcia, M.T., Castillo-Muñoz, N. \& Hermosín-Gutiérrez, I. (2014): Flour of banana (Musa AAA) peel as a source of antioxidant phenolic compounds. Food Res. Int., 55, 397-403.

Singh, B., Singh, J.P., Kaur, A. \& Singh, N. (2016): Bioactive compounds in banana and their associated health benefits - a review. Food Chem., 206, 1-11.

Singleton, V.L., Orthofer, R. \& Lamuela-Raventos, R.M. (1999): Analysis of total phenols and other oxidation substrates and antioxidants by means of Folin-Ciocalteu reagent. Methods Enzymol., 299, 152.

Someya, S., Yoshiki, Y. \& OKubo, K. (2002): Antioxidant compounds from bananas (Musa Cavendish). Food Chem., $79(3), 351-354$

Wachirasiri, P., Julakarangka, S. \& WanlaPa, S. (2009): The effects of banana peel preparations on the properties of banana peel dietary fibre concentrate. Songklanakarin J. Sci. Technol. (SJST), 31(6), 605-611.

Watanabe, M., Ohshita, Y. \& Tsushida, T. (1997): Antioxidant compounds from buckwheat (Fagopyrum esculentum Möench) hulls. J. Agr. Food Chem., 45(4), 1039-1044.

Wu, P.P., MA, G.Z., Li, N., DEnG, Q., Yin, Y.Y. \& HuAng, R.Q. (2015): Investigation of in vitro and in vivo antioxidant activities of flavonoids rich extract from the berries of Rhodomyrtus tomentosa (Ait.) Hassk. Food Chem., 173, 194-202.

XIE, F., WANG, Y.Q., Wu, J.H. \& WANG, Z.W. (2017): Insoluble dietary fibers from Angelica keiskei by-product and their functional and morphological properties: Functional and morphological properties of insoluble dietary fibers. Starch-Starke, 69, 1-12. 